\title{
Correction to: Alginate-chitosan/MWCNTs nanocomposite: a novel approach for sustained release of Ibuprofen
}

\author{
Azeem Bibi ${ }^{1} \cdot$ Sadiq-ur-Rehman ${ }^{1}$ (D) Tasleem Akhtar $^{2} \cdot$ Kalsoom Akhtar $^{1} \cdot$ Muhammad Farooq $^{3}$. \\ Muhammad Imran Shahzad ${ }^{4}$
}

Published online: 15 January 2021

(C) The Polymer Society, Taipei 2021

Correction to: Journal of Polymer Research https://doi.org/10.1007/s10965-020-02342-8

The original version of this article unfortunately contained a mistake. The names of the authors were presented incorrectly as:

Bibi Azeem, Sadiq-ur-Rehman, Akhtar Tasleem, Akhtar Kalsoom, Farooq Muhammad, Shahzad Muhammad Imran.

The correct names should be:

Azeem Bibi, Sadiq-ur-Rehman, Tasleem Akhtar, Kalsoom Akhtar, Muhammad Farooq, Muhammad Imran Shahzad.

The names are shown correctly in this Erratum paper and the original article has been corrected.

Publisher's Note Springer Nature remains neutral with regard to jurisdictional claims in published maps and institutional affiliations.

The original article can be found online at https://doi.org/10.1007/ s10965-020-02342-8.

Sadiq-ur-Rehman

srkhattak@gmail.com

1 Department of Chemistry, University of Azad Jammu and Kashmir, Muzaffarabad, Pakistan

2 Department of Zoology, University of Azad Jammu and Kashmir, Muzaffarabad, Pakistan

3 NCE in Physical Chemistry, University of Peshawar, Peshawar, Pakistan

4 Nano Sciences and Technology Department, National Center for Physics, Islamabad, Pakistan 